\title{
MOVIMENTO DE PROFESSORES E TRANSIÇÃO DEMOCRÁTICA EM MATO GROSSO DO SUL (1979-1985) ${ }^{1}$
}

\author{
Amarilio Ferreira Jr. \\ Universidade Federal de São Carlos (UFSCar) \\ ferreira@ufscar.br
}

\section{RESUMO:}

Este artigo tem como objeto de estudo, com base numa perspectiva marxista, o movimento sindical protagonizado pelos professores públicos em Mato Grosso do Sul durante a transição democrática ocorrida entre 1979 e 1985. A criação de Mato Grosso do Sul, em 1979, após a divisão de Mato Grosso uno, impôs a necessidade de formação de um sistema estadual de educação pública do ensino de $1^{\circ}$ e $2^{\circ}$ graus na nova unidade federativa. E, por conseqüência, iniciou-se o processo de constituição da categoria social dos professores públicos e as suas demandas por melhores condições de vida e de trabalho. Em pleno contexto da ditadura militar (1964-1985), os professores sul-mato-grossenses formaram um amplo movimento associativista reivindicatório que os transformaram num dos principais atores sociais na luta contra o regime político imposto depois de 1964. As dissensões que se estabeleceram entre os professores e os primeiros governos de Mato Grosso do Sul vincaram a própria institucionalidade da escola pública de $1^{\circ}$ e $2^{\circ}$ graus. Portanto, parte-se do pressuposto de que o estudo de tais conflitos possibilita traçar, pelo viés da luta sindical travada pelo movimento de professores, uma panorâmica histórica sobre a educação sulmato-grossense na sua gênese.

Palavras-chave: História da Educação; Movimento de Professores; Políticas Educacionais.

\section{TEACHER'S MOVEMENT AND THE DEMOCRATIC TRANSITION IN MATO GROSSO DO SUL (1979-1985)}

\begin{abstract}
:
This study's object, in a Marxist perspective, is the union movement played by the public teachers in Mato Grosso do Sul during the democratic transition that took place between 1979 and 1985. The establishment of Mato Grosso do Sul, in 1979, after the split of unite Mato Grosso, imposed the formation of a state system of public education for $1^{\text {st }}$ and $2^{\text {nd }}$ grades. Consequently, the composition of public teacher's social category and it's demands for better conditions of life and labor began. On military despotism framework, teachers formed a great joint movement that turned the category into one of the major social artists on the fight against the political regime imposed after 1964. The disagreement between teachers and the earliest authorities in Mato Grosso do Sul accented the legality of public $1^{\text {st }}$ and $2^{\text {nd }}$ grades school. Thus, based on the premise that the study of these conflicts allow to draw, by the syndicalism fight approach, a historical scene of the education on Mato Grosso do Sul.
\end{abstract}

Key-words: History of Education; Teacher's Movement; Educational Polices. 


\title{
Introdução
}

Quando a ditadura militar instalou o primeiro governo preposto de Mato Grosso do $\mathrm{Sul}^{2}$, em 1979, o movimento de professores do ensino público de $1^{\circ}$ e $2^{\circ}$ graus também se mobilizou para criar a sua entidade representativa. Assim, em Campo Grande, capital do novo ente federativo republicano, foi instituída a assembléia geral de delegados municipais, cujo objetivo era fundar a Federação de Professores de Mato Grosso do Sul (FEPROSUL) $^{3}$. Destarte, a FEPROSUL constituiu-se na estrutura associativista do movimento de professores desde a secessão de Mato Grosso em dois estados distintos.

A luta sindical protagonizada pela FEPROSUL foi, aqui, tomada como uma manifestação particular do movimento sindical geral das classes trabalhadoras brasileiras, consequentemente, expostas às mesmas vicissitudes sociais determinadas pelas relações de produção capitalistas que imperavam no Brasil na passagem das décadas de 1970 para 1980. Além disso, a FEPROSUL, como organização de cunho sindical no âmbito societário de classes, representava e defendia os interesses por melhores condições de vida e de trabalho de uma categoria profissional específica do setor de serviços públicos.

Além disso, o movimento sindical desencadeado pela categoria dos professores do ensino público estadual estava inserido, em decorrência do processo de crescimento autoritário da economia brasileira durante o regime militar ${ }^{4}$, no âmago das transformações que alteraram o perfil da anatomia social das classes médias ${ }^{5}$. Neste contexto, a trajetória da luta sindical dos professores de $1^{\mathrm{o}}$ e $2^{\mathrm{a}}$ graus foi interpretada por Angelina Peralva assim:

\begin{abstract}
Atores de uma sociedade moderna, onde a escolarização e um elemento central do processo de desenvolvimento e a institucionalização das relações de trabalho uma conquista datada, os professores tem sido, nos últimos anos, obrigados a se empenhar em uma luta mortal pela preservação de direitos trabalhistas que, para outras categorias; de trabalhadores, podem ser consideradas como já adquiridos. Ao mesmo tempo foram, talvez, mais intensamente afetados pela proletarização do que qualquer outra categoria de trabalhadores urbanos no Brasil ${ }^{\mathbf{6}}$.
\end{abstract}

Já do ponto de vista da conjuntura política da época, a transição democrática, patrocinada por um conjunto de forças sócio-políticas da sociedade civil, caracterizou-se, a partir do final dos anos 1970, tanto por elementos de continuidade quanto de ruptura com o ordenamento jurídico que o Estado assumiu após o golpe militar de $1964^{7}$. Deste modo, o quadro institucional da transição, depois da vitória da chapa Tancredo Neves (PMDB) / José Sarney (FL) no Colégio Eleitoral, em 1985, foi conceituado por Luiz Werneck Vianna da seguinte forma:

Desde a eleição de Tancredo, por transição devemos entender processo social da transição mais governo da transição. Mas, qual a política do governo da transição? Não ter política alguma, pois há dois anos coexiste com as instituições do antigo regime, promete o que não pode cumprir, com o congelamento de preços, cumpri o que ninguém pediu, como o Cruzado II, e estimula impasses para ter o que fazer com sua administração ${ }^{8}$.

Assim sendo, a transição democrática foi marcada por uma descontinuidade sem ruptura em relação à estrutura jurídico-econômica herdada do regime militar. Ou seja: a 
consolidação das liberdades políticas e a substituição da lógica econômica implantado após 1964 transformaram-se nas principais contradições da transição entre o regime militar e o Estado de direito democrático. A luta sindical travada pela FEPROSUL, portanto, estava encravada num contexto de crise sócio-política no qual os trabalhadores brasileiros lutavam, a um só tempo, tanto por melhores condições de vida e de trabalho com pelas liberdades democráticas.

\section{A fundação da FEPROSUL}

A fundação da FEPROSUL pela categoria profissional dos professores públicos estaduais de $1^{\circ}$ e $2^{\circ}$ graus foi condicionada por dois elementos sócio-econômicos contraditórios, mas engendrados pelo mesmo processo de modernização excludente das relações capitalistas de produção vividas pela sociedade brasileira durante a vigência do modelo econômico implantado pelo regime militar?

De um lado, a conjuntura nacional impregnada pelo primeiro ciclo de greves operárias do $\mathrm{ABC}$ paulista que deu origem a uma nova concepção de luta sindical e possibilitou um novo nível de consciência de classe do movimento sócio-político dos trabalhadores brasileiros ${ }^{\mathbf{1 0}}$. Do outro, o fato de que a criação de Mato Grosso do Sul resultou da combinação de interesses econômico-políticos de dois protagonistas sociais das classes dominantes brasileiras, ou seja: os grupos oligárquicos latifundiários, do sul de Mato Grosso, e a aliança empresarial-militar que empalmou o poder após 1964. Em outras palavras: a fundação da FEPROSUL resultou do confronto de dois paradigmas societários antinômicos e complementares. Ou seja, do choque das relações entre o moderno (as influências das greves operárias do ABC paulista como manifestação do conflito de capital versus trabalho) e o arcaico (a implantação do novo estado da Federação nos marcos de uma organização econômica determinada por relações agrárias com remanescentes précapitalistas de produção) ${ }^{\mathbf{1 1}}$.

O movimento de professores, como não poderia deixar de ser, não ficou imune a essa contradição não antagônica estabelecida entre o arcaico e o moderno. Ela manifestouse, essencialmente, no caráter que a estrutura associativista da FEPROFUL assumiu. A preponderância de concepções sócio-políticas atrasadas, num contexto de novas relações sociais geradas pelo capitalismo urbano-industrial, revelou-se no fato de que os professores públicos estaduais de $1^{\circ}$ e $2^{\circ}$ graus não conseguiram construir uma estrutura sindical capaz de provocar uma ruptura definitiva com o modelo sindical originado da Era Vargas (19301945). A FEPROSUL foi erigida com base nos princípios corporativistas, ou seja, uma estrutura associativista e verticalizada, a partir da cúpula, tal como estabelecia o modelo imposto pela CLT (1943) ${ }^{\mathbf{1 2}}$. Dito de outra forma: o movimento de professores sul-matogrossense optou por um tipo de estrutura sindical concebido pelas elites dirigentes que, historicamente, sempre se posicionaram contra as liberdades democráticas no transcurso do período republicano brasileiro.

Assim sendo, a vinculação da FEPROSUL com o ente jurídico que determinava a existência de uma estrutura sindical de caráter corporativista subordinada ao Estado materializava a essência da contradição entre o atraso e o novo gerados pelo capitalismo brasileiro de então. As características constitutivas assumiram, fundamentalmente, as seguintes dimensões: (I) os estatutos da FEPROSUL reproduziam o conceito de associação sindical de grau superior contida no interior do Artigo 538 da $\mathrm{CLT}^{\mathbf{1 3}}$; (II) a própria CLT, no Artigo 566, entretanto, não reconhecia o direito de sindicalização para qualquer tipo de categoria profissional de servidor público; e (III) quando da sua fundação, no final dos 
anos 1970, o movimento operário brasileiro já tinha avançado de forma decisiva rumo à construção de um projeto de sindicalismo classista, autônomo, pluralista e de massas que culminou, no início da década de 1980, na fundação da CONCLAT (1981) e da CUT $(1983)^{14}$.

Ora, a FEPROSUL como representação de cunho sindical de uma categoria profissional de servidores estaduais era uma organização que se situava exclusivamente no plano da sociedade civil, com seus estatutos registrados em cartório e não no Ministério do Trabalho. Por conseguinte, o movimento dos professores poderia ter estruturado uma concepção sindical em consonância com o que tinha de mais avançado no movimento operário e não ao contrário.

De resto, a estrutura organizacional da FEPROSUL, réplica do modelo sindical estatal, acabava por debilitar o bloco político de oposição à ditadura militar, na medida em que não privilegiava a democracia como a principal questão societária daquele momento histórico da transição. Assim, a organização associativista representativa do movimento de professores sul-mato-grossense assumiu a seguinte configuração:

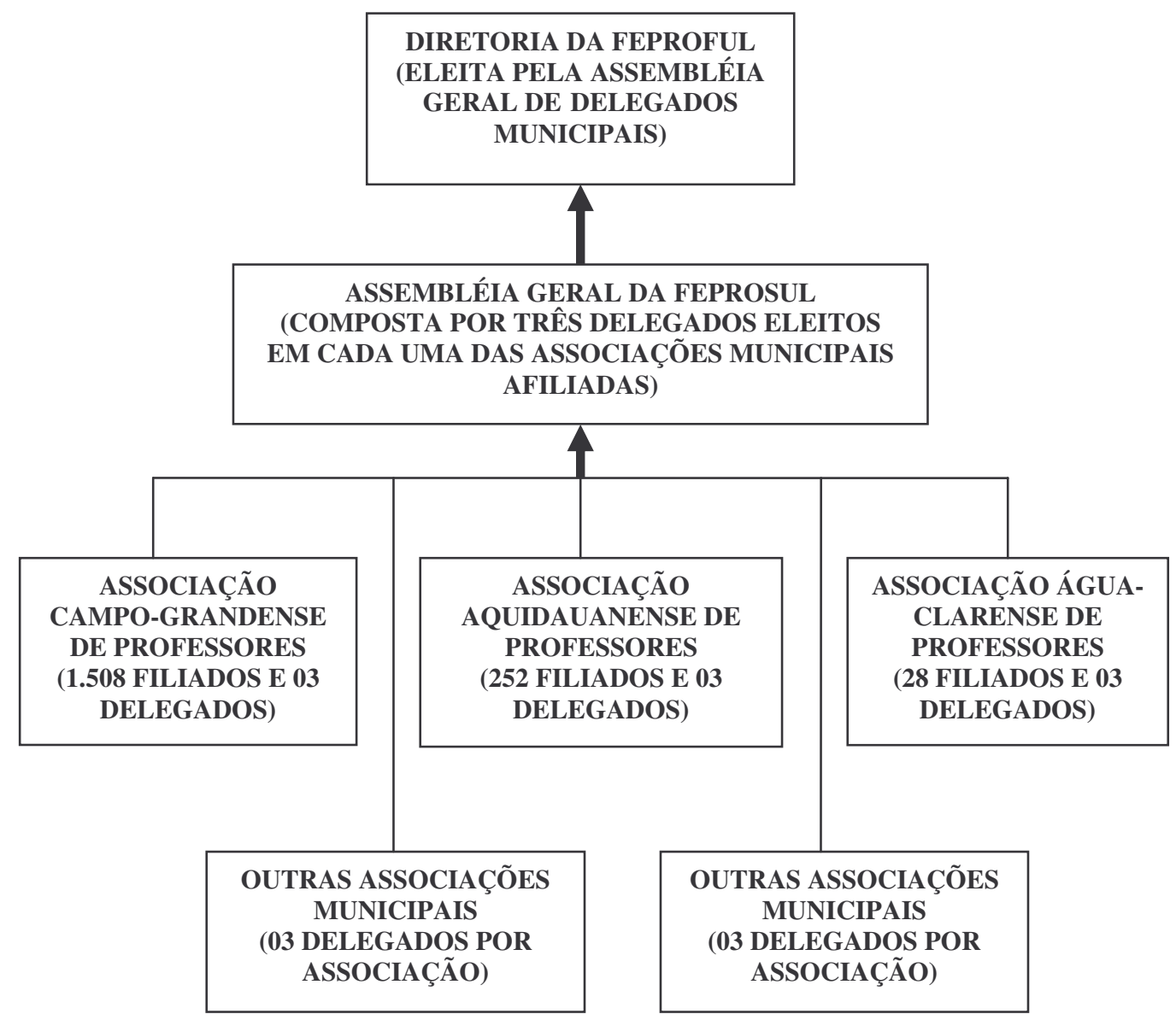




\section{A FEPROSUL e os primeiros governos de Mato Grosso do Sul}

A institucionalização da crise política que marcou os primórdios da existência de Mato Grosso do Sul - no curto interregno da sucessão de três governadores: Harry Amorim Costa (1979), Marcelo Miranda (1979/1980) e Pedro Pedrossian (1980/1983) teve suas raízes assentadas em dois fatores que se complementavam: (I) em âmbito nacional, os mecanismos constitucionais que conferiam caráter autoritário ao poder tecnocrata-militar imposto pela violação das instituições democráticas, desde o início dos anos 1960; e (II) no plano estadual, a disputa renhida entre os vários grupos representativos dos interesses sócio-econômicos das classes dominantes, marcadamente formada por latifundiários, pela hegemonia política do poder local.

As relações entre estes três governos (ARENA/PDS) de Mato Grosso do Sul e o movimento de professores foram marcadas por posições de adesão e repulsão. Num primeiro momento, a FEPROSUL, organização situada no contexto da sociedade civil, colocou-se na posição de colaboração e em outro assumiu uma postura de independência político-sindical diante da ordem estatal estabelecida pelo regime militar.

Num primeiro momento, a relação entre a FEPROSUL e os governos nomeados pelo regime militar foi pautada pelas questões econômicas e funcionais da categoria dos professores de $1^{\circ}$ e $2^{\circ}$ graus. Pois, a situação do professorado público estadual, herdada do quadro funcional de Mato Grosso uno, encontrava-se numa situação social que obscurecia os seus próprios limites anatômicos. Ou seja, as péssimas condições de vida e trabalho a que os professores estavam submetidos provocaram certa ruptura com os limites sociais aceitáveis para uma categoria de trabalhadores públicos. Em relação às questões salariais, acumulava-se uma defasagem de $60,78 \%$ em comparação com o custo de vida registrado no período entre 1975 e $1978^{\mathbf{1 5}}$, configurando-se, assim, a contradição essencial do modelo econômico do regime militar: crescimento econômico baseado no arrocho salarial das classes trabalhadoras. Já no âmbito das relações funcionais, havia pendente uma série de problemas empregatícios não resolvidos, tais como: ausência de concursos públicos periódicos; prestação de serviços sem contrato de trabalho; critérios de admissão e demissão baseados nos interesses políticos governistas; e a inexistência de um Estatuto do Magistério tal como previa a Lei $5.692 / 71^{16}$.

Todavia, o movimento de professores implementou uma política sindical, apesar deste quadro de vida material da categoria, que se colocava a reboque das iniciativas governamentais, tal como evidencia esta passagem da "Carta ao Governador Harry Amorim":

[...] imbuídos do mais elevado espírito de cooperação, com o propósito de ajudarem na construção de Mato Grosso do Sul e conferindo a Vossa Excelência o voto de confiança, tão necessário para o harmônico relacionamento entre os poderes constituídos e as entidades de classes ${ }^{17}$.

Ou então, como na resolução política do I Seminário das Associações Municipais de Professores de Mato Grosso do Sul: "[...]os profissionais do ensino, conscientes de suas responsabilidades, assim como dos seus direitos, estarão prontos a uma colaboração mais eficiente com o governo em prol do ensino (...)"18.

O segundo momento teve início quando uma delegação de observadores enviada pela FEPROSUL, em 1980, participou do XIII Congresso da Federação dos Professores do Brasil (CPB). O contato com o movimento sindical de professores de $1^{\circ}$ e $2^{\circ}$ graus 
organizado nacionalmente, com sua pluralidade de tendências político-sindicais ${ }^{\mathbf{1 9}}$, marcou um ponto de inflexão na trajetória sindical da FEPROSUL.

Acompanhando as deliberações aprovadas no congresso da CPB, a FEPROSUL realizou, no início do ano letivo de 1980, uma passeata do conjunto da categoria ${ }^{\mathbf{2 0}}$, em Campo Grande, como momento de mobilização privilegiado para reivindicar a implementação, por parte do governo estadual, das questões salariais e funcionais que se arrastavam desde a criação de Mato Grosso do Sul, entre as quais destacamos: o enquadramento funcional dos professores remanescentes do antigo quadro de servidores de Mato Grosso uno; concurso público; aplicação da tabela salarial já reajustada; e a adoção do piso salarial para a categoria ${ }^{21}$. A capacidade organizativa de mobilizar uma manifestação de massas, passeata com mais de seis mil professores, possibilitou estabelecer um acordo em torno dos principais pontos da pauta de reivindicações apresentada pela FEPROSUL.

Esta etapa da luta sindical protagonizada pela FEPROSUL terminou durante o último governo preposto pelo regime militar, isto e, após o pleito que restabeleceu as eleições diretas para governadores de Estados, em 1982. Durante o governo Pedro Pedrossian (PDS), portanto, a FEPROSUL teve o Estatuto do Magistério aprovado, regime jurídico que regulamentava as relações funcionais entre o Estado e a categoria dos professores. Quando a Lei n. ${ }^{\circ}$ 04/81 foi aprovada na Assembléia Legislativa o líder do governo, Deputado Ary Rigo (PDS), afirmou:

O trabalho conjugado de todos os partidos, bem como a participação direta dos professores na elaboração do projeto, ao lado dos três governadores que o Estado já teve. Idealizado por Harry A. Costa, o Estatuto teve a sua conclusão no governo de Marcelo e foi finalmente emendado por propostas de Pedrossian ${ }^{22}$.

Além disto, marcaram também esta fase dois acontecimentos interligados importantes: a primeira greve organizada pela FEPROSUL em decorrência do fato de que o governo, no ano de 1981, só ofereceu $15 \%$ de reajuste salarial, enquanto a inflação tinha sido próxima de $108 \%{ }^{23}$. E a represália governamental, motivada pela greve massiva da categoria $^{24}$, que culminou na criação artificial de uma nova entidade sindical estadual paralela a FEPROSUL. A fundação da Associação de Professores de Mato Grosso do Sul $(\mathrm{APMS})^{\mathbf{2 5}}$ estabeleceu uma pluralidade sindical que remeteu a FEPROSUL ao isolamento, com relação aos encaminhamentos das questões referentes ao mundo do trabalho subjacente ao sistema de ensino público estadual.

\section{A FEPROSUL e o Governo Wilson Barbosa Martins (1983/1986)}

A inexistência de um movimento operário fabril com tradição de luta sindical, em função do predomínio das relações agrárias de produção, evidenciou de forma valorativa as manifestações massivas - passeatas e greves - protagonizadas pela categoria profissional dos professores públicos de $1^{\circ}$ e $2^{\circ}$ graus durante as administrações dos governos estaduais nomeados pelo regime militar.

No contexto de uma sociedade civil fragilizada, frente a um Estado que fazia uso da hegemonia de classe pela injunção quase que exclusiva da coerção, a FEPROSUL acabou por assumir um determinado tipo de luta sindical que se caracterizava pela resistência ao isolamento imposto pelo governo Pedro Pedrossian. Como conseqüência ao 
recrudescimento gerado pelos embates com o governo, o corporativismo da estrutura sindical, fundada em 1979 pelo movimento de professores, ficou ainda mais realçado. Entretanto, com a vitória de Wilson Barbosa Martins (PMDB), nas eleições diretas para governador realizadas em 1982, inaugurou-se uma nova conjuntura institucional nas relações entre a sociedade civil e sociedade política em Mato Grosso do Sul $^{\mathbf{2 6}}$.

Essa nova conjuntura institucional passou a encerrar em si mesma uma contradição de duplo significado: de um lado, o fato de que aquele governo estadual tinha sido eleito por um amplo espectro de forças sócio-políticas, inclusive com a participação da FEPROSUL, para poder fazer frente ao regime militar; do outro, a manutenção da concepção sindical corporativista da FEPROSUL e as políticas de democratização do sistema de ensino estadual adotadas pelo governo oposicionista ao regime militar.

Ao mesmo tempo, as relações entre a FEPROSUL e o governo Wilson Barbosa Martins foram estabelecidas nos marcos das demandas acumuladas pelo movimento sindical dos professores desde o primeiro governo de Mato Grosso do Sul, em 1979. As pendências se expressavam por meio de uma intensa pauta de reivindicações, entre as quais se destacavam: o pagamento de aulas excedentes; descontos financeiros da greve de 1981; pagamento de salários atrasados; incentivos financeiros para a regência de salas de aulas da $1^{\mathrm{a}}$ a $4^{\mathrm{a}}$ séries; ascensão e progressão funcional; Comissão de Valorização do Magistério; realização de concursos públicos; eleições para diretores de escolas e Agentes Regionais de Educação; participação no Conselho Estadual de Educação; política educacional; e reajuste salarial semestral ${ }^{27}$.

A começar deste enquadramento determinado pela pauta de reivindicações da FEPROSUL, o primeiro conflito se estabeleceu quando o governo nomeou para a Secretaria de Educação um nome, oriundo da frente democrática peemedebista ${ }^{28}$, que não tinha saído das fileiras do magistério de $1^{\circ}$ e $2^{\circ}$ graus. O secretario estadual de educação, Leonardo Nunes da Cunha, passou a ser hostilizado pela cúpula dirigente da FEPROSUL em função do fato de que ele não era um professor ${ }^{29}$. Pois, a direção da entidade do magistério considerava que somente um professor seria capaz de entender as questões problemáticas afetas à educação pública de $1^{\circ}$ e $2^{\circ}$ graus. Em outros termos: a FEPROSUL fundamentava-se em conceitos políticos que propugnavam pela organização da sociedade com base nas categorias profissionais, ou seja, num entendimento societário que se explicitava na conciliação dos interesses econômicos das categorias e não nos conflitos de interesses fundamentados no conflito entre as classes sociais.

Depois, com a realização do I Congresso de Educação para a Democracia, convocado pelo governo peemedebista para se definir uma proposta educacional geral para a educação pública ${ }^{30}$, produziu-se um impacto político que estilhaçou contradições ideológicas num amplo espectro de forças sócio-políticas comprometidas com o tempo pretérito da transição democrática. Embotada pelo viés do corporativismo, a FEPROSUL igualmente se revelou incapaz de avaliar corretamente o significado da dimensão social que a proposta pedagógica, resultante do Congresso, desempenhava para a estratégia da luta em favor da democracia. O diapasão ideológico conservador tonificava as criticas com argumentos que variavam na forma, mas não no antagonismo explícito, tais como:

É manobra típica dos comunistas... É impor suas idéias através de uma lavagem cerebral para deteriorar a formação de uma juventude cheia de esperança... (Deputado Jesus Gaeta - PMDB) ${ }^{\mathbf{3 1}}$.

Que democracia e educação são estas, onde se tira pedagogos da direção da escola e se coloca professores leigos? (Deputado Ary Riga - PDS) ${ }^{\mathbf{3 2}}$.

Ele, o secretário Leonardo Nunes da Cunha, além das críticas dos parlamentares, de uma forma geral, não conta com a simpatia de Valter 
Pereira de Oliveira e Jesus Gaeta que falam no avanço da ideologia comunista no setor educacional' (Jornal Correio do Estado) ${ }^{\mathbf{3 3}}$.

Ledo engano, o Congresso não passou de uma encenação, que não convenceu o público presente e mais ainda, usou os professores que deram o máximo de si. Leonardo enganou a todos: governo, professores, alunos e comunidade (Jornal Quadro Verde) ${ }^{34}$.

Desta forma, a FEPROSUL perdia de perspectiva as seguintes considerações: (I) de que a luta pela consolidação da democracia era uma questão fundamental para a derrota do status quo imposto pelo regime militar; (II) o fato de que ela própria tinha reivindicado do governo Wilson Barbosa Martins uma política educacional com mecanismo de democratização do ensino público de $1^{\circ}$ e $2^{\circ}$ graus; e (III) de que a composição das forças políticas do governo estadual eram as mesmas que, no fundamental, opunham-se contra o regime militar com base em uma unidade na diversidade de posições ideológicas.

Em seguida, um novo embate se travou entre a FEPROSUL e o governo estadual de oposição ao regime militar. No segundo semestre de 1983, o movimento de professores deflagrou uma ampla mobilização por reajuste salarial, pois havia uma defasagem salarial acumulada desde o começo de 1983, quando o governo havia concedido um reajuste de 97\%. De um lado, a FEPROSUL reivindicava a adoção de um piso de três salários mínimos como pressuposto para a melhoria das condições de trabalho da categoria; do outro, a relutância do governo em compreender que as expectativas das massas populares, em relação às oposições vitoriosas, recaiam sobre as modificações concretas das condições de vida, tais como os salários. Além disso, há que se considerar que o início dos anos 1980 foi marcado por um processo de recessão no modelo econômico do regime militar que agravou ainda mais o quadro social imposto pela política de arrocho salarial ${ }^{35}$.

O impasse só foi resolvido após uma greve massiva e prolongado da categoria dos professores públicos estaduais de $1^{\circ}$ e $2^{\circ}$ graus. Configurando-se, assim, a interpretação elaborada por Angelina Peralva para explicar a trajetória destes novos protagonistas sociais no contexto da transição democrática. Ela afirmou que:

[...] houve um tempo em que era simples dizer contra quem se lutava. A ditadura era o obstáculo visível à realização das aspirações democráticas de toda a sociedade, inclusive das aspirações particulares do magistério. Hoje, a decepção de uma enorme parcela do movimento face a antigos aliados - uma enorme massa de políticos de tradição progressista, principalmente (mas não apenas) aqueles filiados ao PMDB - divide a categoria e complica a definição do adversário ${ }^{36}$.

De resto, mais três episódios merecem importância, pois refletiam uma nova postura política do governo em relação ao mundo do trabalho que emanava do sistema estadual de ensino básico: (I) a aprovação das Leis $n .^{\circ} 476^{37}$ e n. $^{\circ} 603^{38}$ que instituíam, respectivamente, o reajuste salarial semestral e o piso de 2,5 salários mínimos para a categoria dos professores estaduais; (II) a aprovação da Lei Complementar $n .{ }^{\circ} 15^{39}$ que colocava dirigentes da estrutura sindical da FEPROSUL a disposição integral as tarefas da entidade; e (III) a publicação do Decreto n. ${ }^{\circ} 3004^{40}$ que fixava as normas para as eleições diretas de diretores das escolas estaduais de Mato Grosso do Sul.

Todavia, a última decisão do governo, de institucionalizar as eleições para diretores de escolas, rearticulou novamente aquele bloco político conservador ${ }^{41}$ que resistia às mudanças democráticas implementadas pela frente oposicionista incrustada no interior do PMDB, ou seja: estabeleceu-se novamente uma reação à política educacional defendida 
pelo governo estadual que ia da FEPROFUL ao PDS, passando por setores conservadores do próprio PMDB. Atendendo a solicitação da entidade do magistério com o argumento de que não havia sido consultada previamente e porque também tinha divergências com alguns pontos da medida, o governo suspendeu a adoção das eleições diretas para diretores das escolas estaduais de $1^{\circ}$ e $2^{\circ}$ graus ${ }^{42}$.

\section{Conclusão}

Paradoxalmente, a FEPROSUL, no contexto da transição democrática, teve a organicidade da sua estrutura sindical ainda mais fortalecida. Aliás, o próprio professor Antonio Carlos Biffi, ex-presidente da entidade na época, foi quem reconheceu:

Começamos a ter dispensa dos presidentes das associações em 1984, menos de um ano de governo Wilson. Mesmo assim, logo depois da aprovação desta lei da 'licença sindical nos fizemos uma greve de ma is de trinta dias e em nenhum momento o governo ameaçou derrubar essa lei, respeitando a estrutura sindical que nos tínhamos implantado. E importante salientar nesse per iodo de 1983 a 1984, quero dar esse testemunho, o respeito das instituições democráticas. Isso foi muito salutar. Mesmo com essas instituições atacando o governo como nos fazíamos ${ }^{43}$.

Nos marcos deste entendimento, a luta sindical empreendida pela FEPROSUL esteve pautada, no período analisado, por elementos de caráter economicista, isto é, marcada pela ausência de uma unidade dialética entre a luta econômica e a luta política que caracterizava a atuação do movimento sindical das classes trabalhadoras no âmbito mais geral da sociedade brasileira de então. Em virtude disto, a luta sindical protagonizada pela FEPROSUL, no contexto da transição democrática, não se materializou numa proposta política substantiva para a baixa qualidade de ensino que assolava a escola pública estadual de $1^{\circ}$ e $2^{\circ}$ graus de Mato Grosso do Sul. Em outros termos, a entidade do magistério não foi capaz politicamente de colocar em questão a escola de Estado como uma instituição pública que garantisse a igualdade educacional entre os filhos das classes populares e os dos grupos sociais que dominavam a sociedade sul-mato-grossense.

Em síntese, a trajetória sindical da FEPROSUL, no período de 1979 a 1986, ficou caracterizada pela ruptura entre as lutas econômica e política, na qual prevaleceu apenas o entendimento regulado pelos interesses econômico-corporativos. A corrente sindical que dirigiu a Federação associativista do magistério público sul-mato-grossense no interregno em tela refletia o estágio de autoconsciência social da própria categoria profissional que representava. A sua concepção de luta sindical encontrava-se, até aquele momento, no nível das reivindicações econômico-corporativas. Se nos reportarmos a Gramsci ${ }^{44}$, compreenderemos que a direção do movimento de professores sul-mato-grossense ainda não tinha atingido a fase "em que se adquire a consciência de que os próprios interesses corporativos [...]superam o círculo corporativo, de grupos meramente econômicos, e podem e devem tornar-se os interesses de outros grupos". 


\section{Fontes}

\section{Documentos Governamentais}

BRASIL. Poder Executivo. Fundação Instituto Brasileiro de Geografia e Estatística. Lei Complementar n. ${ }^{\circ} 31$, de 11 de outubro de 1979. In: . Mato Grosso do Sul. Rio de Janeiro: IBGE, 1979, p. 151-158.

MATO GROSSO DO SUL. Poder Executivo. Decreto n. ${ }^{\circ}$ 174. Fixa o salário básico das categorias funcionais de Professor e de especialista de Educação e dá outras providências. Diário Oficial, Campo Grande, 21 jun.1979. p. 01.

MATO GROSSO DO SUL. Poder Executivo. Lei n. ${ }^{\circ}$ 56. Fixa novos valores e reajusta vencimentos, salários e proventos dos servidores do Estado e dá outras providências. Diário Oficial, Campo Grande, 28 mar. 1980. p. 01-04.

MATO GROSSO DO SUL. Extrato de Estatuto da Associação de Professores de Mato Grosso do Sul. Diário Oficial, Campo Grande, 25 nov. 1981. p. 60.

MATO GROSSO DO SUL. Poder Executivo. Lei Complementar n. ${ }^{\circ} 15$. Dá nova redação ao art. 56 da Lei Complementar n. ${ }^{\circ}$ 4, de 12.01.81, que "dispõe sobre o estatuto do Magistério Estadual e dá outras providências". Diário Oficial, Campo Grande, 05 jan. 1984. p. 01.

MATO GROSSO DO SUL. Poder Executivo. Lei n. ${ }^{\circ}$ 476. Dispõe sobre a semestralidade dos reajustes de vencimentos dos servidores da Administração Pública Estadual, reajusta os valores de vencimentos, salários, proventos e pensões do pessoal civil no Poder Executivo e no Tribunal de Contas e dá outras providências. Diário Oficial, Campo Grande, 29 out. 1984. p. 01-02.

MATO GROSSO DO SUL. Poder Executivo. Decreto n. ${ }^{\circ}$ 3.004. Dispõe sobre a escolha, mediante eleição direta de Diretores e Diretores-Adjuntos das Unidades Escolares da Rede Estadual de Ensino e dá outras providências. Diário Oficial, Campo grande, 06 maio 1985. p. 01-02.

MATO GROSSO DO SUL. Poder Executivo. Lei n. ${ }^{\circ}$ 603. Fixa o piso salarial do integrante do Grupo Magistério, e dá outras providências. Diário Oficial, Campo Grande, 12 dez. 1985. p. 01.

\section{Periódicos (Jornais \& Revistas)}

ABREU, Dulce Regina de. Mais salário, melhor ensino: a educação e o movimento dos professores. Revista Contraponto, Rio de Janeiro, n. 4, p. 95-106, jan. - jun. 1980.

A "CARTA Aberta ao Governador Cássio Leite de Barros". Quadro Verde, Dourados, 17 set. 1978, p.3.

A "CARTA ao Governador Harry Amorim". Quadro Verde, Dourados, 25 out. 1978, p. 23.

A ERA Leonardo. Quadro Verde, Campo Grande, Abr. 1985. p. 01.

AS OPINIÕES sobre o polêmico documento. Jornal da Cidade, Campo Grande, 23-29 out. 1983. Caderno 1, p.6.

ARROYO, Miguel Gonzáles. O acontecimento em educação: o movimento dos professores. Aconteceu Especial, 19 - Educação no Brasil 1987-1988. São Paulo, p.155-157, 1991.

ARROYO, Miguel Gonzáles. Operários e educadores se identificam: que rumo tomará a educação brasileira? Revista Educação \& Sociedade, São Paulo, n. 5, p. 5-23, jan. 1980. 
BARRETO, Angela Maria Rabelo Ferreira. Professores do ensino de primeiro grau: quem são, onde estão e quanto ganham. Estudos em Avaliação Educacional, São Paulo, 3: 11-43, jan./jun. 1991.

CUNHA, Luiz Antônio. Educação na transição para a democracia: o caso do Brasil. Revista Educação e Realidade, Porto Alegre, n. 13, p. 23-37, jul/dez. 1988.

ELEIÇÕES escolares revogadas por Wilson. Jornal da Manhã, Campo Grande, 22 maio 1985, Caderno 1, p. 04.

ENGUITA, Mariano F. A ambigüidade da docência: entre o profissional e a proletarização. Revista Teoria \& Educação, Porto Alegre, n. 4, p. 41-61, 1991.

FAGUNDES, José; Lúcio, KREUTZ. Movimento docente no período de abertura política: 1978-1979. Revista Educação e Realidade, Porto Alegre, n. 17 p. 62-72, jul/dez. 1992.

FERREIRA Jr., Amarilio; DUARTE, Alice. CPB na luta por uma educação democrática. Jornal Voz da Unidade, São Paulo, 06-12 jan. 1981. Caderno 1, p. 12.

FERREIRA Jr., Amarilio. A greve dos professores. Jornal da Cidade, Campo Grande, 2329 nov. 1987. Caderno 1. p. 2.

FERREIRA Jr., Amarilio; BITTAR, Marisa. A ditadura militar e a proletarização dos professores. Educação \& Sociedade, Campinas, v. 27, n. 97, p. 1159-1179, set./dez. $2006 b$.

HOBSBAWM, E. Mudança no proletariado provoca crise nas esquerdas. Folha de São Paulo, São Paulo, 1991. Caderno 4, p. 04.

LEONARDO fortalecido por Wilson. Correio do Estado, Campo Grande, 14 out. 1933. $1^{\circ}$ Caderno, p.l.

MAIS professores aderem à greve na criação da APMS. Diário da Serra, Campo Grande, 27 nov. $1981.1^{\circ}$ Caderno, p.4.

MILHOMEM, Gumercindo. Que sindicato? Teoria e Debate, São Paulo, 2, (7), 66-69, jul.set. 1989.

OPOSIÇÃO vence e elege Wilson. Diário da Serra, Campo Grande, 21 nov. 1982, $1^{\circ}$ Caderno, p.01.

PERALVA, Angelina Teixeira. E o movimento de professores da rede pública? Cadernos de Pesquisa, São Paulo, 64: 64-66, fev. 1988.

PROFESSOR já tem Estatuto aprovado. Diário da Serra, Campo Grande, 03 dez, 1980. $1^{\circ}$ Caderno, p. 1.

PROFESSORES sentem-se traídos com a indicação do secretário de educação. $\boldsymbol{O}$ Progresso, Dourados, 26-27 fev. 1983. $1^{\circ}$ Caderno, p.06.

PROTESTO, passeata e novas promessas. Diário da Serra, Campo Grande, 28 mar. 1980. Caderno A, p. 04.

RIBEIRO, Maria Luíza Santos. Movimento de professores: as greves de 78 e 79 no estado de São Paulo. ANDE, São Paulo, 1, (4) 26-30, 1982.

RODRIGUES, Leôncio Martins. A sindicalização da classe média. Folha de São Paulo, São Paulo, 24 de maio de 1992, Caderno 1, p. 03.

ZANETI, Hermes. Entrevista: É hora de unir e construir a democracia. Jornal Voz da Unidade, São Paulo, 06-12 jan. 1981. Caderno 1, p. 12. (Entrevistadores: Alice Duarte \& Amarilio Ferreira Jr.).

\section{Entrevistas}

BIFFI, Antônio Carlos. Entrevista, Campo Grande, 29 abr. 1991.

MARTINS, Wilson Barbosa. Entrevista, Campo Grande, 02 jun. 1991. 


\section{Bibliografia}

ABRAMO, Perseu. O professor, a organização corporativa e a ação política. In: CATANI, Denise Bárbara; MIRANDA, Hercília T. de et al. Universidade, escola e formação de professores. São Paulo: Brasiliense, 1986. p.77-84.

ALBUQUERQUE, Manoel Maurício. Pequena história da formação social brasileira. Rio de Janeiro: Graal, 1981. 728 p.

ALVES, Maria Helena Moreira. Estado e oposição no Brasil (1964-1984). $2^{\text {a }}$ Ed. Petrópolis: Vozes, 1984. 337p.

CAMPANHOLE, Adriano; CAMPANHOLE, Hilton L. Consolidação das Leis do Trabalho e Legislação Complementar. 50 ad. São Paulo: Editora Atlas, 1979. 1018 p.

CARONE, Edgard. Movimento operário no Brasil (1964-1980). São Paulo: DIFEL, 1984. $311 \mathrm{p}$.

DINIZ, Eli; BOSCHI, Renato et al. Modernização e consolidação democrática no Brasil: dilemas da Nova República, São Paulo: Vértice, 1989. 190 p.

FERNANDES, Florestan. A formação política e o trabalho do professor. In: CATANI, Denise Bárbara; MIRANDA, Hercília T. de et al (Org.). Universidade, escola e formação de professores. São Paulo: Brasiliense, 1986. p. 13-37.

FERREIRA Jr., Amarilio. A FEPROSUL e a luta sindical dos professores estaduais de $1^{o}$ e $2^{o}$ graus: 1979-1986. Campo Grande: UFMS, 1992. 130 p. Dissertação (Mestrado em Educação). Centro de Ciências Humanas e Sociais, UFMS.

FERREIRA Jr., Amarilio. Professores e sindicalismo em Mato Grosso do Sul: 1979-1986. Campo Grande: Editora da UFMS, 2003.

FERREIRA Jr., Amarilio; BITTAR, Marisa. Proletarização e sindicalismo de professores na ditadura militar (1964-1985). São Paulo: Pulsar, 2006a. 105p.

GRAMSCI, Antonio. Caderno 13 (1932-1934): Breves notas sobre a política de Maquiavel. In: Cadernos do cárcere. Tradução: Carlos Nelson Coutinho et al. Rio de Janeiro: Civilização Brasileira, 2000. v. 3, p. 11-109.

IANNI, Octavio. O professor como intelectual: cultura e dependência. In: CATANI, Denise Bárbara; MIRANDA, Hercília T. de et al (Org.). Universidade, escola e formação de professores. São Paulo: Brasiliense, 1986. p. 40-49.

KECK, Margaret. O "Novo Sindicalismo" na Transição Brasileira. In: STEPAN, Alfred (Org.). Democratizando o Brasil. Tradução: Ana Luíza Pinheiro et al. Rio de Janeiro: Paz e Terra, 1988. p. 381-440.

MILLS, Wrigth. A nova classe média. $3^{\mathrm{a}}$ ed. Rio de Janeiro: Zahar, 3.079. 380 p.

PERALVA, Angelina Teixeira. Professores: um movimento a se repensar. Aconteceu Especial, 19 - Educação no Brasil 1987-1988. São Paulo, p.158-161, 1991.

PREGO, Niso. Profissionalização do magistério e suas entidades de classe. Congresso Brasileiro de Educação. IV Conferência Brasileira de Educação: Educação e Constituinte, 1986, Goiânia. Anais. São Paulo: Cortez Editora, 1986. p. 538-545. (Tomo I).

RIBEIRO, Maria Luisa S. A formação política do professor de $l^{\circ}$ e $2^{\circ}$ graus. São Paulo: Cortez Editora, 1984. 280 p.

RIBEIRO, Maria Luíza Santos. A profissionalização do magistério e as entidades de classe. Congresso Brasileiro de Educação. IV Conferência Brasileira de Educação: Educação e Constituinte, 1986, Goiânia. Anais. São Paulo: Cortez Editora, 1986. p. 533-537. (Tomo I).

SADER, Emir. A transição no Brasil; da ditadura à democracia?. São Paulo: Atual Editora, 1990. 92 p. 
KIDM0RE, Thomas. Brasil: de Castelo a Tancredo. $4^{\text {a }}$ Ed. Rio de Janeiro: Faz e Terra, 1988. 608 p.

STEPAN, Alfred. Democratizando o Brasil. Rio de Janeiro: paz e Terra 1308. p. 137-197.

VIANNA, Luiz Werneck. Liberalismo e sindicato no Brasil. $2^{\text {a }}$ Ed. Rio de Janeiro: Paz e

Terra, 1978. 288 p.

VIANNA, Luiz Werneck. A transição: da Constituição à sucessão presidencial. Rio de Janeiro: DEVAN, 1989. 174 p.

\section{Notas}

${ }^{1}$ Este artigo é uma síntese do terceiro capítulo da dissertação de mestrado intitulada "A FEPROSUL e a luta sindical dos professores estaduais de $1^{\circ}$ e $2^{\circ}$ graus: 1979-1986", defendida, em setembro de 1992, no Programa de Pós-Graduação em Educação do Centro de Ciências Humanas e Sociais (CCHS) da Universidade Federal de Mato Grosso do Sul, sob a orientação do Prof. Dr. Jose Luis Sanfelice.

${ }^{2}$ A criação de Mato Grosso do Sul deu-se por meio da Lei Complementar n. ${ }^{\circ}$ 31, de 11 de outubro de 1977, durante o governo do general-presidente Ernesto Geisel (BRASIL. Fundação Instituto Brasileiro de Geografia e Estatística. Mato Grosso do Sul, p. 151-158).

${ }^{3}$ A FEPROSUL deixou de representar, em 1989, apenas os antigos professores de $1^{\circ}$ e $2^{\circ}$ graus. No seu XVI Congresso Estadual, realizado em Amambaí (MS), foram aprovadas, entre outras, duas propostas: (a) transformar a Federação não só em representante dos professores, mas, também, dos funcionários técnicoadministrativos das escolas públicas; e (b) substituir o seu nome: de FEPROSUL para Federação dos Trabalhadores em Educação de Mato Grosso do Sul (FETEMS). Assim, a FETEMS é a sucedânea da FEPROSUL.

${ }^{4} \mathrm{O}$ chamado "milagre econômico" estabeleceu um crescimento em que "o PIB subiu à média anual de 10,9 por cento de 1968 a 1974" (KIDMORE, Thomas. Brasil, p. 276.).

${ }^{5}$ Uma análise explicativa das transformações sofridas pela estratografia das classes médias, como resultado social do modelo econômico da ditadura militar, encontra-se em: DINIZ, Eli; BOSCHI, Renato et al. Modernização e consolidação democrática no Brasil: DIN1Z et al, p.25.

${ }^{6}$ PERALVA, Angelina Teixeira. Professores, p. 158.

${ }^{7}$ Uma panorâmica geral do caráter autoritário do Estado brasileiro durante o regime militar encontra-se sistematizado em: ALVES, Maria Helena Moreira. Estado e Oposição no Brasil (1964/1984), 1984.

${ }^{8}$ VIANNA, Luiz Werneck. A transição: da Constituição à sucessão presidencial, p.19-20.

${ }^{9}$ Sobre as discrepâncias que se estabeleceram entre crescimento econômico e indicadores sociais durante a ditadura militar, deve-se consultar: DINIZ, Eli; BOSCHI, Renato et al. Modernização e consolidação democrática no Brasil: DIN1Z et al, p.25.

${ }^{10}$ As referências sobre essas transformações, manifestas no âmbito do movimento sindical da classe operaria brasileira, encontram-se em: HOBSBAWM, Eric. Mudança no proletariado provoca crise nas esquerdas. Folha de São Paulo, São Paulo, 1991. Caderno 4, p. 04.

${ }^{11}$ A participação na arrecadação do ICM por setor e a estratificação da população economicamente ativa (PEN), em termos de percentagens, não deixam dúvidas sobre o caráter agrário da economia de Mato Grosso do Sul. Em relação ao ICM (1980): primário 55\%; secundário 12\%; terciário 33\%. Quanto à PEA (1980): primário 36\%; secundário 18\%; terciário 43\% (MATO GROSSO DO SUL. Diretrizes da Ação do Governo, OF/GOV/MS/n. ${ }^{\circ} 181 / 64$, p.10-11).

${ }^{12}$ Uma sistemática análise sobre o significado do corporativismo sindical, gerado CLT, encontra-se em: VIANNA, Luiz Werneck. Liberalismo e sindicato no Brasil, 1978.

${ }^{13}$ Os Artigos $39^{\circ}$ e $41^{\circ}$ dos estatutos da FEPROSUL determinavam eleições indiretas para a diretoria da entidade a partir de uma assembléia composta por três delegados, das associações municipais de professores, independentemente do número de membros da categoria por base territorial, tal como estabelecia a CLT (CAMPANHOLE, Adriano; CAMPANHOLE, Hilton L. Consolidação das Leis do Trabalho e Legislação Complementar, p. 125).

${ }^{14}$ KECK, Margaret. O "Novo Sindicalismo" na Transição Brasileira, p. 409.

${ }^{15}$ A "Carta ao Governador Harry Amorim". Quadro Verde, Dourados, 25 out. 1978, p. 2-3.

${ }^{16}$ A "Carta Aberta ao Governador Cássio Leite de Barros". Quadro Verde, Dourados, 17 set. 1978, p.3. Durante o ano de 1978, com sua estrutura jurídica já definida, o território correspondente ao atual Estado de Mato Grosso do Sul foi administrado pelo Estado de Mato Grosso uno, cujo governador foi Cássio Leite de Barros. 


\footnotetext{
${ }^{17}$ A "Carta ao Governador Harry Amorim". Quadro Verde, Dourados, 25 out. 1978, p. 2-3.

${ }^{18} \mathrm{O}$ documento resultante do I Seminário de Associações Municipais de Professores de Mato Grosso do Sul (Arquivo da FEPROSUL/79).

${ }^{19}$ Várias tendências políticas de esquerda atuavam no interior da Confederação dos Professores do Brasil (CPB) no começo dos anos 1980, tais como: PCB, PC do B, MR-8 e todas as tendências de esquerda que organizaram o PT.

${ }^{20}$ Protesto, passeata e novas promessas. Diário da Serra, Campo Grande, 28 mar. 1980. Caderno A, p. 04.

${ }^{21}$ De acordo com o Decreto n. ${ }^{\circ} 174$, de 21 de junho de 1979, a tabela salarial da categoria funcional do magistério era determinada pelos coeficientes existentes entre os níveis e as classes que enquadrava diferentes frações de professores por habilitação e tempo de serviço. E mais, pela Lei $\mathrm{n}^{\circ} 56$, de março de 1980, o governo tinha concedido um reajuste salarial que perfazia um montante de 50\% (MATO GROSSO DO SUL, Decreto n. ${ }^{\mathbf{0}} \mathbf{1 7 4}$, p. 01.; MATO GROSSO DO SUL, Lei n. ${ }^{\mathbf{0}} \mathbf{5 6}$, p. 01-04).

${ }^{22}$ Professor já tem Estatuto aprovado. Diário da Serra, Campo Grande, 03 dez, 1980. $1^{\circ}$ Caderno, p. 1.

${ }^{23}$ O IPC acusava, em abril de 1981, um aumento na ordem de $106.40 \%$ acumulados nos últimos doze meses, segundo o IBGE/DPE e DESIP/DIPLA.

${ }^{24}$ Mais professores aderem à greve na criação da APMS. Diário da Serra, Campo Grande, 27 nov. 1981. $1^{\circ}$ Caderno, p.4.

${ }^{25}$ A APMS foi fundada no dia 23/11/81 e teve o extrato dos seus Estatutos publicados no Diário Oficial do Estado de Mato Grosso do Sul (MATO GROSSO DO SUL. Extrato de Estatuto da Associação de Professores de Mato Grosso do Sul, 25 nov. 1981. p. 60).

${ }^{26}$ Oposição vence e elege Wilson. Diário da Serra, Campo Grande, 21 nov. 1982. $1^{\circ}$ Caderno, p.01.

${ }^{27}$ "As reivindicações do Magistério ao Governo Estadual", documento que foi protocolado pela FEPROSUL na Governadoria em 26/06/83 (Arquivo da FEPROSUL/83).

${ }^{28}$ A nomeação do secretario de educação contemplou a esquerda organizada em torno das propostas congressuais do PCB (MARTINS, Wilson Barbosa. Entrevista, Campo Grande, 02 jun. 1991).

${ }^{29}$ Professores sentem-se traídos com a indicação do secretário de educação. O Progresso, Dourados, 26-27 fev. 1983. $1^{\circ}$ Caderno, p.06.

${ }^{30}$ Em consonância com as diretrizes educacionais determinadas nacionalmente pelo PMDB vários estados implementaram propostas educacionais alternativas, como: São Paulo, Minas Gerais e Paraná (Congresso mineiro de educação quer mudança radical no ensino. Folha de São Paulo, São Paulo, 25 set, 1983. $3^{\circ}$ Caderno p. 23).

${ }^{31}$ As opiniões sobre o polêmico documento. Jornal da Cidade, Campo Grande, 23-29 out. 1983. Caderno 1, p.6.

${ }^{32}$ As opiniões sobre o polêmico documento. Jornal da Cidade, Campo Grande, 23-29 out. 1983. Caderno 1, p.6.

${ }^{33}$ Leonardo fortalecido por Wilson. Correio do Estado, Campo Grande, 14 out. $1933.1^{\circ}$ Caderno, p.l.

${ }^{34}$ A era Leonardo. Quadro Verde, Campo Grande, Abr. 1985. p. 01.

${ }^{35}$ Sobre a crise econômica que ocorreu durante o governo do general-presidente João Figueiredo, deve-se consultar: ALVES, Maria Helena Moreira. Estado e oposição no Brasil (1964-1984), p.289.

${ }^{36}$ PERALVA, 1991, p.161.

${ }^{37}$ MATO GROSSO DO SUL, Lei n. ${ }^{\circ}$ 476, 29 out. 1984. p. 01-02.

${ }^{38}$ MATO GROSSO DO SUL, Lei n. ${ }^{\mathbf{6} 63}, 12 \mathrm{dez} .1985$. p. 01.

${ }^{39}$ MATO GROSSO DO SUL, Decreto n. ${ }^{\circ} \mathbf{3 . 0 0 4}, 06$ maio 1985. p. 01-02.

${ }^{40}$ MATO GROSSO DO SUL, Lei Complementar n. ${ }^{\mathbf{1}}$ 15, 05 jan. 1984. p. 01.

${ }^{41}$ Eleição para diretores: nova jogada de Wilson, O Combate, Corumbá, 11-17 maio 1985, $1^{\circ}$ Caderno, p. 05.

${ }^{42}$ Eleições escolares revogadas por Wilson. Jornal da Manhã, Campo Grande, 22 maio 1985, Caderno 1, p. 04.

${ }^{43}$ BIFFE, Antônio Carlos. Entrevista, Campo Grande, 29 abr. 1991.

${ }^{44}$ GRAMSCI, Antonio. Caderno 13 (1932-1934), p. 41.
}

Artigo recebido em: 10/03/2009

Aprovado para publicação em: 15/05/2009 